\title{
RECTANGULAR MICROSTRIP ANTENNA WITH SWASTIK ELECTROMAGNETIC BAND GAP STRUCTURE
}

\author{
Savita M. Shaka ${ }^{1}$, Vani R. $\mathbf{M}^{\mathbf{2}}$, Prashant R.T ${ }^{3}$ and Hunagund P.V ${ }^{4}$

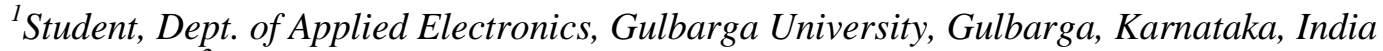 \\ ${ }^{2}$ Head, USIC, Gulbarga University, Gulbarga, Karnataka, India \\ ${ }^{3}$ Student, Dept. of Applied Electronics, Gulbarga University, Gulbarga, Karnataka, India \\ ${ }^{4}$ Professor, Dept. of Applied Electronics, Gulbarga University, Gulbarga, Karnataka, India
}

\begin{abstract}
This paper reports the Rectangular Microstrip Antenna with Swatik Electromagnetic Band Gap (EBG) structure on the ground plane. The performance of the proposed antenna are compared with the Conventional Rectangular Microstrip antenna (CRMA).It is observed that there is significant increase of bandwidth and better suppression of back radiation than the Conventional Rectangular Microstrip Antenna. The antenna operating in frequency range of 5-15 GHz which is one of the most usable for wireless application such as WLAN, Wimax etc..
\end{abstract}

Keywords: Rectangular microstrip antenna, swastik electromagnetic band gap (EBG), bandwidth.

\section{INTRODUCTION}

Recently a growing demands of microwave \& wireless communication system in various applications resulting in an interest to improve antenna performance. Therefore the selection of microstrip antenna is suitable to apply at various fields such as telecommunication, medical application satellite \& military because antennas offer an attractive solution to easy of fabrication low profile, planar configuration due to this it is more commonly used in modern wireless communication system[1-2]. In spite of this the microstrip antenna are suffering from narrow bandwidth, spurious feed radiation, poor polarization, gain and tolerance problem. Bandwidth can be increased but at the cost of size of the patch, making bulky and large. To overcome this problem, a multi layer dielectric substrate has been used to improve bandwidth. Beyond certain thickness of substrate, the efficiency of antenna starts decreasing due to more surface wave generation [3-4]. The surface wave generation can be reduced in using Electromagnetic Band Gap (EBG) structure. In the last decade, periodic EBG structures were the focus of much attention due to their promising applications in microwave circuit and antenna design[5]. These EBG structure exhibit wide bandpass and band rejection properties at certain microwave frequencies. This unique property has been utilized in enhancing the performance of microstrip antenna [6-7].

In this paper a Rectangular Microstrip Antenna loaded with Swastika EBG in the ground plane (RMASWEBG) has designed which gives better bandwidth and gain enhancement compared to Conventional Rectangular Microstrip antenna (CRMA).

\section{ANTENNA DESIGN}

The proposed antennas are designed using a low cost glass epoxy material of dielectric constant $\varepsilon r=4.4$, substrate of thickness $\mathrm{h}=1.6 \mathrm{~mm}$. The substrate is backed by a ground plane with dimension $\mathrm{Lg}=40 \mathrm{~mm}$ and $\mathrm{Wg}=40 \mathrm{~mm}$. The width of the CRMA is usually chosen to be larger than the length of the patch, $\mathrm{L}$ to get higher bandwidth. The antenna is designed to operate at frequency $6 \mathrm{GHz}$. The CRMA is shown in the Fig1 (a) and Fig-1 (b) shows the photographic view of the CRMA. A high impedance swastik EBG structures (RMASWEBG) is introduced in the ground of the CRMA. The antenna RMASWEBG is shown in Fig-2 (a), the photographic view of the RMASWEBG is shown in Fig-2(b). The SWEBG structure prohibits propagation of electromagnetic waves in a certain frequency bands. This suppresses the surface waves and hence gives enhancement in the performance of the proposed antenna.

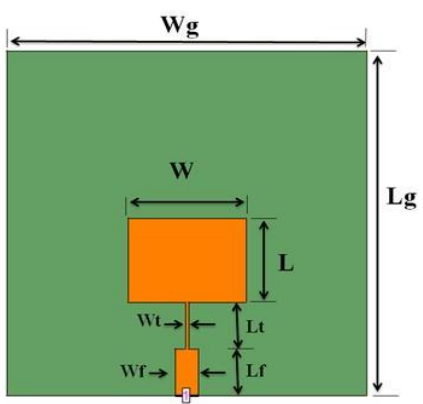

Fig-1 (a): Top View of the CRMA 


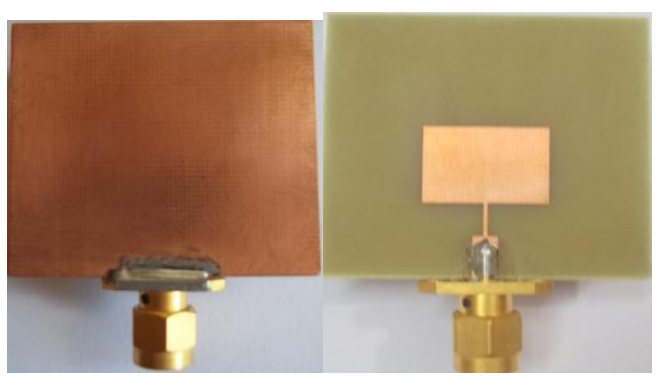

Fig-1 (b): Photographic Top \& Bottom view of RMASWEBG

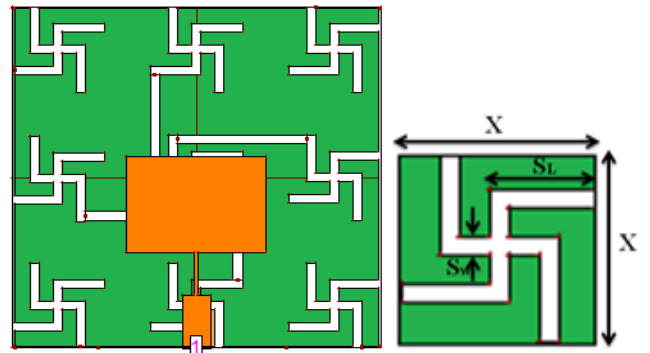

Fia-2 (a): Top RMASWEBG and a enlarged geometry of single EBG

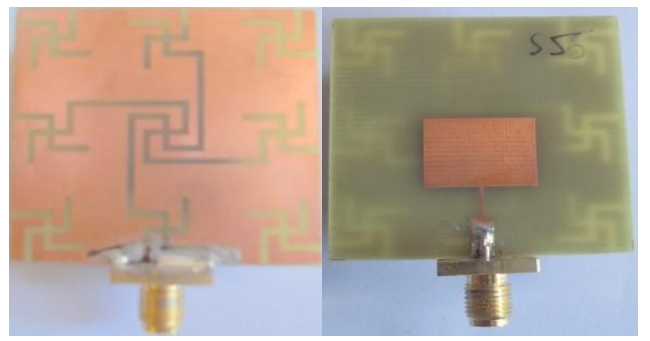

Fig -2 (b): Photographic view of top and bottom RMASWEBG

Table-1: Geometrical configuration of the CRMA \& RMASWEBG

\begin{tabular}{|c|c|c|}
\hline $\begin{array}{c}\text { Antenna } \\
\text { part }\end{array}$ & Parameters & Value \\
\hline \multirow[t]{2}{*}{ Patch } & Length(L) & $15.24 \mathrm{~mm}$ \\
\hline & Width(W) & $11.33 \mathrm{~mm}$ \\
\hline \multirow{2}{*}{$\begin{array}{c}\text { Microstrip } \\
\text { Feed }\end{array}$} & Length $\left(\mathrm{L}_{\mathrm{f} 50}\right)$ & $6.187 \mathrm{~mm}$ \\
\hline & Width( $\left.\mathrm{W}_{\mathrm{f50}}\right)$ & $3.060 \mathrm{~mm}$ \\
\hline \multirow{2}{*}{$\begin{array}{l}\text { Quaterwave } \\
\text { Transformer }\end{array}$} & Length $\left(\mathrm{L}_{\mathrm{t}}\right)$ & $4.922 \mathrm{~mm}$ \\
\hline & Width(Wt) & $0.5 \mathrm{~mm}$ \\
\hline \multirow{5}{*}{$\begin{array}{c}\text { Swastik } \\
\text { EBG } \\
\text { structures }\end{array}$} & Length(X) & $8 \mathrm{~mm}$ \\
\hline & Width $(\mathrm{X})$ & $8 \mathrm{~mm}$ \\
\hline & $\mathrm{Gap}(\mathrm{G})$ & $8 \mathrm{~mm}$ \\
\hline & $\begin{array}{l}\text { Length of the } \\
\text { slot(SL) }\end{array}$ & $4 \mathrm{~mm}$ \\
\hline & $\begin{array}{c}\text { Width of the } \\
\operatorname{slot}(\mathrm{Sw})\end{array}$ & $1 \mathrm{~mm}$ \\
\hline
\end{tabular}

\section{EXPERIMENTAL RESULTS \& DISCUSSIONS}

The designed antennas have been experimentally studied using Vector Network Analyzer (Rohde \& Schwarz, Germany make ZVK model 1127.8651). Fig-3(a) shows the measured return loss (RL) versus frequency characteristics for CRMA \& SEBGRMA. The results shows that patch antenna CRMA resonates at $5.99 \mathrm{GHz}$ with total available impedance bandwidth $\mathrm{BW} 120 \mathrm{MHz}$ at $-10 \mathrm{~dB}$ i.e., $2.03 \%$ covering the frequency range $5.794 \mathrm{GHz}$ to $5.914 \mathrm{GHz}$. Then for antenna RMASWEBG BW1 covers the frequency range $5.593 \mathrm{GHz}$ to $5.815 \mathrm{GHz} \& \mathrm{BW} 26.675 \mathrm{GHz}$ to $6.920 \mathrm{GHz}$ and BW3 $12.60 \mathrm{GHz}$ to $15.01 \mathrm{GHz}$. The total impedance bandwidth for BW1+BW2+BW3 is $467 \mathrm{MHz}$ i.e., $(222+245+241) 287 \mathrm{MHz}$ i.e. $(3.898+3.625+17.67) 25.19 \%$ impedance bandwidth resonating at covering c-band for RMASWEBG. The result of CRMA \& RMASWEBG is shown in table-2.

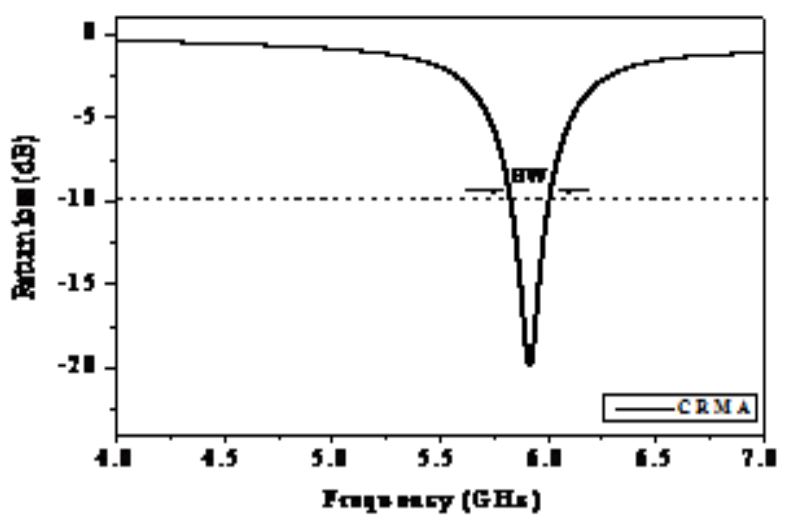

Fig- 3(a): Return loss Characteristics of CRMA

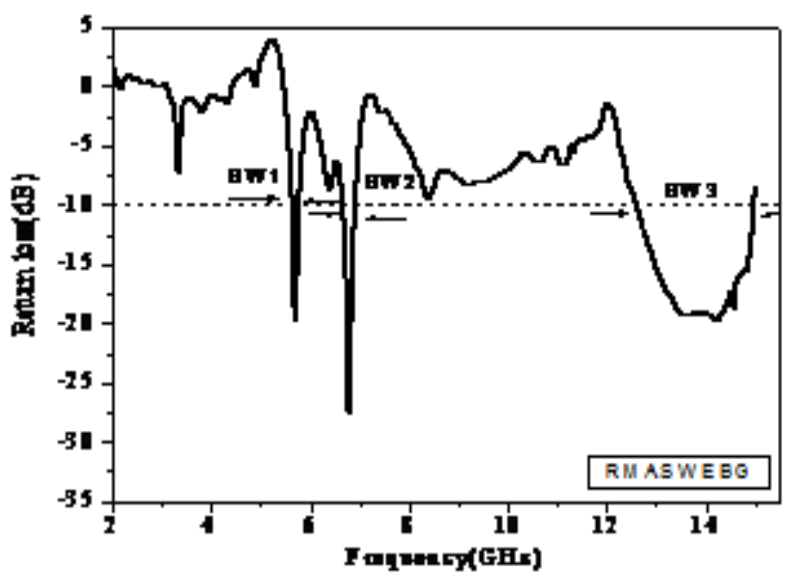

Fig-3 (b) Return loss Characteristics of RMASWEBG 
Table-2: Results of CRMA \& RMASWEBG

\begin{tabular}{|c|c|c|c|c|c|c|}
\hline Antenna & $\begin{array}{c}\text { No. of } \\
\text { Bands }\end{array}$ & $\begin{array}{c}\text { Return loss } \\
(\mathbf{d B})\end{array}$ & $\begin{array}{c}\text { Resonant } \\
\text { Freq. } \\
(\mathbf{G H z})\end{array}$ & $\begin{array}{c}\text { Band Width } \\
\text { in MHz }\end{array}$ & $\begin{array}{c}\text { Band Width in } \\
\mathbf{( \% )}\end{array}$ & $\begin{array}{c}\text { Overall } \\
\text { Band Width in } \\
(\boldsymbol{\%})\end{array}$ \\
\hline CRMA & 01 & -15.25 & 5.99 & 176 & 2.93 & 2.05 \\
\hline RMASWEBG & 03 & -19.59 & 5.69 & $\mathrm{BW} 1=22$ & 3.89 & 25.193 \\
\hline
\end{tabular}

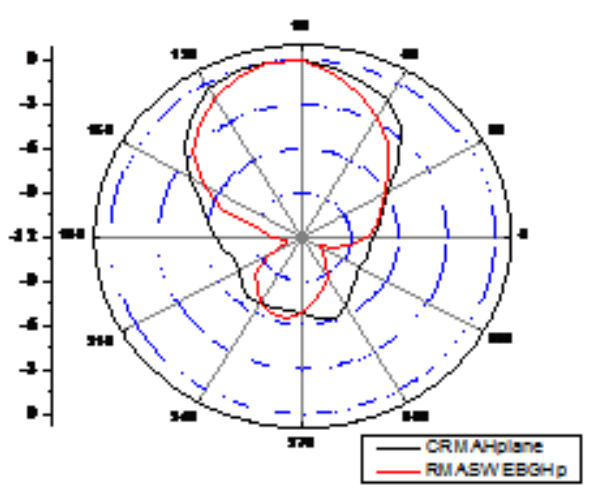

Fig.-4. H-plane radiation patterns of CRMA \& RMASWEBG

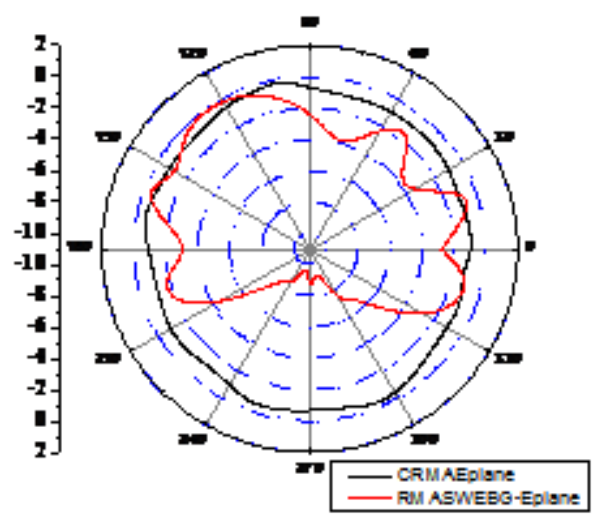

Fig.-5. E-plane radiation patterns of CRMA \& RMASWEBG

Fig-4 shows the results of experimental comparison of E-plane co-polar radiation pattern of the designed antenna with CRMA. From the figure it is clear that the back lobe radiations of RMASWEBG are suppressed compared to the CRMA, by embedding the swastika EBG structure on the Ground plane. Fig5 shows the radiation pattern of $\mathrm{H}$-plane co-polar with broad side with not much variation as in the E-plane radiation.

\section{CONCLUSIONS}

The study has demonstrated that, the proposed antenna with swastika EBG structure in the ground plane gives the impedance bandwidth of $287 \mathrm{MHz}(25.19 \%)$ as compared to the CRMA . also there is a reduction in back lobe reduction in compared to conventional antenna. This antenna can be used for wireless application.

\section{ACKNOWLEDGMENTS}

The authors would like to convey thanks to the department of science \& technology (DST) government of India, New Delhi, for sanctioning vector Network analyzer to this department under FIST project.

\section{REFERENCES}

[1]. Bahl and P. Bhartia, "Microstrip Antennas",Dedham, Ma, Artech house, 1981.

[2]. Gnanam Gnanagurunation and krishnaswamy T. Selvan, "Improved radiation characterstics of a patch antenna with square slot EBG", In IEEE International RF and Microwave conference(RFM 2011), 12th -14th December 2011, seremban, Malaysia pp. 381-383.

[3]. M. Rahman and M. Stuchly, "Wide - band microstrip patch antenna with planar PBG structure ", in Proc. IEEE APS Dig., vol 2, July 2001, pp.486-489.

[4]. Sudhakar Srivastava, Rajesh Nema,Pankaj kumar Goswami, "A New Design Improvement Of Microstrip UShape Antenna For Bandwidth Enhancement Using EBG Structure Deformation", In International Journal of Engineering Science and Technology(IJEST), vol.4 No. 06 June 2012, pp, 2962-2966.

[5]. Santosh Tyagi,kirti vyas, " Bandwidth Enhancement using slotted U- shape Microstrip antenna with PBG ground.", In International Journal of technology \& Engineering Research (IJATER), vol.3, issue 1, jan. 2013.

[6]. Raj Kumar, George Mathai nad J.P. Sinde"Design of compact mulitiband EBG and Effect OF antenna Performance" In International Journal of Recent Trends in Engineering, Vo1 2, No. 5, November 2009,pp 254-258.

[7]. B.Ramesh, Dr. V rajya Lakshmi," Design of A Rectangular Microstrip Antenna Using EBG Structure", In 
Internationl Journal of Engineering Rearch \& Technology(IJERT), Vol. 2 Issue 7, July-2013,pp 2233-2236.

\section{BIOGRAPHIES}

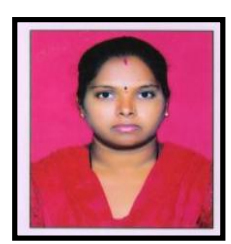

Savita M Shaka received her M Sc from the department of Applied Electronics from Gulbarga University, Gulbarga in the year 2006 and her M Phil from the same department in year 2008. Currently she is pursuing her Ph.D in the field of Microwave Antennas from the department of Applied Electronics, Gulbarga University, Gulbarga.

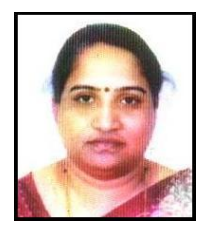

Vani R. M. received her B.E. in Electrical and Electronics from the B.I.ET., Davanagere and M.Tech in Industrial Electronics from S.J.C.E., Mysore, Karnataka. She has received her Ph.D in Applied Electronics from Gulbarga University, Gulbarga, India, in year 2005. She is working as Reader \& Head, University Science Instrumentation Center, Gulbarga University, Gulbarga, since 1995. She has more than 85 research publications in national and international reputed journals/Conference proceedings. she presented the research papers in National/ International conferences in India and abroad. She has conducted several courses, workshops for the benefits of faculties and field engineers. Her areas of interest are microwave antennas, PC based instrumentation, Embedded controllers and Wireless communication. She has one UGC major research project to her credit

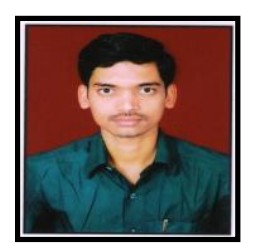

Prashant $\mathbf{R} \mathbf{T}$ received his $\mathrm{M}$ Sc from the department of Applied Electronics Gulbarga University, Gulbarga in the year 2011. He worked as a Project Fellow in the UGC sponcerd Majore Reserch Project 20122013. Currently he is persuing his Ph.D in the field of Microwave Antennas from the department of Applied Electronics, Gulbarga University, Gulbarga.

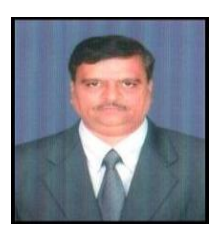

P. V. Hunagund, received his M.Sc and Ph.D from the Dept. of Applied electronics, Gulbarga University, Gulbarga, in the year 1982 and 1992 respectively. He is working as professor and chairman of Applied Electronics department, Gulbarga University, Gulbarga. $\mathrm{He}$ has more than 25 research publications in national and international reputed journals, more than 85 research publications in international symposium/Conferences. He presented the research papers in National/International conferences in India and abroad. He has guided many Ph.D and M.Phil students. He has three major research projects at his credit. 